\title{
Keith Negus
}

\section{The Work of Cultural Intermediaries and the Enduring Distance between Production and Consumption}

Published as Negus, Keith R., 2002. The Work of Cultural Intermediaries and the Enduring Distance between Production and Consumption. Cultural Studies, 16 (4). pp. 501-515.

For the published version please visit: http://www.informaworld.com/smpp/content $\sim \mathrm{db}=$ all? content=10.1080/09502380210139089

\begin{abstract}
This article raises some critical questions about cultural intermediaries as both a descriptive label and analytic concept. In doing so, it has two main aims. First, it seeks to provide some clarification, critique and suggestions that will assist in the elaboration of this idea and offer possible lines of enquiry for further research. Second, it is argued that whilst studying the work of cultural intermediaries can provide a number of insights, such an approach provides only a partial account of the practices that continue to proliferate in the space between production and consumption. Indeed, in significant ways, a focus on cultural intermediaries reproduces rather than bridges the distance between production and consumption. The paper focuses on three distinct issues. First, some questions are raised about the presumed special significance of cultural intermediaries within the production/consumption relations of contemporary capitalism. Second, how 'creative' and active cultural intermediaries are within processes of cultural production is discussed. Third, specific strategies of inclusion/exclusion adopted by this occupational grouping are highlighted in order to suggest that access to work providing 'symbolic goods and services' is by no means as fluid or open as is sometimes claimed.
\end{abstract}

The term cultural intermediaries has become increasingly used in recent years, often in a manner that bears little resemblance to its introduction in the writings of Pierre Bourdieu, and its adoption by those who draw on this aspect of his work. The term can be found used in a precise way, but also in a quite casual manner. With this in mind, I want to use this essay to offer both some clarification and to raise some critical questions about the notion of cultural intermediaries. I want to suggest that the significance this label accords to an occupational group and set of working practices is warranted due to the way it directs attention to significant changes brought about by the growth of workers involved in the production and circulation of symbolic forms, and because a 
focus on this type of employment highlights some of the central dilemmas of how to deal with the articulations of production and consumption. As a theoretical analytic category and as a descriptive label for an occupational entity, the notion of new cultural intermediaries provides a number of insights and points to some important lines of enquiry. However, we still have a long way to go before we come close to fully understanding the practices that continue to proliferate in the space between production and consumption, particularly in those gaps opened up by the media, arts, information and entertainment industries. In focusing on debates about the practices that involve the intersection and possible blurring of production/consumption, one of my aims here is to highlight the enduring significance of the distance between production and consumption. There are three distinct areas I wish to focus on. First, I want to address a question that seems obvious, but leads into a number of problems: who are cultural intermediaries and what is their special position in the relations of production/consumption? I then move on to my second question, which concerns how 'creative' and active cultural intermediaries are within processes of cultural production. Third, I want to ask about the strategies of inclusion/exclusion adopted by this occupational grouping.

\section{Cultural intermediaries as a special occupational grouping linking production to consumption}

The term 'cultural intermediaries' was introduced by Pierre Bourdieu in his book Distinction and was associated with his comments on the 'new petite bourgeoisie', a new faction of middle-class workers that has grown in size and influence since the middle of the twentieth century. Although Bourdieu's ideas are derived from detailed studies of work and consumption in France, the concept has certain similarities with what other writers have called a 'service class 'or 'knowledge class'. It refers to those workers engaged in 'occupations involving presentation and representation . . . providing symbolic goods and services' (Bourdieu, 1984: 359). To repeat a much cited passage: 
The new petite bourgeoisie comes into its own in all the occupations involving presentation and representation (sales, marketing, advertising, public relations, fashion, decoration and so forth) and in all the institutions providing symbolic goods and services ... and in cultural production and organization which have expanded considerably in recent years. (1984: 359)

This new petite bourgeoisie distinguish themselves from the old petite bourgeoisie (with its middle brow dispositions) and adopt different orienting practices towards their own 'class' identity. In both their working habits and routines of daily living, this new class faction tends to blur a number of conventional distinctions. Most notable here is the division between high art/popular culture, and the divide between personal taste and professional judgement (or leisure and work). This blurring can be observed in the practices of workers in the media, arts and entertainment industries, and particularly in advertising and marketing, occupations that have become central to the workings of capitalism in general. According to Bourdieu - and also to Mike Featherstone (1991) who adopts the term in his account of postmodern consumer culture - this new class faction implies a certain meeting or point of connection between the disaffected, educated, bohemian middle class and the upwardly mobile, newly educated working class (it is not difficult to see why this grouping might have an appeal for those engaged in doing media and cultural studies).

Bourdieu does not expand on his analysis of this group in any detailed way, and it is rather surprising that there is no real sense of the work of cultural intermediaries in his studies of artistic and literary production (Bourdieu, 1993, 1996). Although focused on nineteenth- and early twentieth-century aesthetic fields, we might have expected to find more detailed references to the emergent groupings and practices that would more widely be recognized as cultural intermediary activity in the latter part of the twentieth century. It has mainly been down to other researchers to begin developing, elaborating or illustrating this idea through empirical research. Here I would include my own work on the music industry in the UK (Negus, 1992), and the USA (Negus, 1999), and in light of this I would like to briefly say something about the value of this notion and why I have used it. 
The central strength of the notion of cultural intermediaries is that it places an emphasis on those workers who come in-between creative artists and consumers (or, more generally, production and consumption). It also suggests a shift away from unidirectional or transmission models of cultural production towards an approach that conceives of workers as intermediaries continually engaged in forming a point of connection or articulation between production and consumption. This is a significant shift from transmission models of cultural production whereby various writers have portrayed the aesthetic economy in terms of analogies with assembly lines, or 'filter flow' systems, tracing the movement of 'raw materials' from creative artist to consumer (see Hirsch, 1972; Peterson, 1976; Ryan and Peterson, 1982).

It also suggests a shift from, or counterbalance to, an emphasis on economic constraints and determinations (from the economic shaping of culture), associated with versions of political economy, towards a concern with how culture shapes the economic. Or, more precisely and in less causal terms, it challenges us to think about the reciprocal inter-relationship of what are often thought of as discrete 'cultural' and 'economic' practices. Hence, Bourdieu's work is pivotal in the resurrection of or return to a 'cultural economy' of social life.

Bourdieu, and those who draw on this aspect of his work, suggests that symbolic production is central to the work of cultural intermediaries, and this frequently means the use of advertising imagery, marketing and promotional techniques. Such symbolic productions are crucial for contemporary commodification to occur. Hence, cultural intermediaries shape both use values and exchange values, and seek to manage how these values are connected with people's lives through the various techniques of persuasion and marketing and through the construction of markets. The aim of numerous workers engaged in promotion and marketing is to link a product to a potential consumer by seeking to forge a sense of identification, whether between a young person and a training shoe, a spectator and a film star, or a listener and a musician. Here, the use of advertising imagery, marketing and promotion are central to the representations through which attempts are made 
to link a product, service or celebrity and a citizen. As new products, celebrities and services are created, so cultural intermediaries become continually involved in explaining to us the use value of these new commodities (why we might need and what we might do with new face creams, training shoes, bendy curved toothbrushes, or young classical singers) and what their exchange value might be (their relative market worth). Hence, the study of cultural intermediaries should provide important insights into the changing dynamics of contemporary capitalism.

However, this approach to these issues creates a number of problems. The concept of cultural intermediaries has been introduced in a way that privileges a particular cluster of occupations. It accords certain workers a pivotal role in these processes of symbolic mediation, prioritizing a narrow and reductionist aesthetic definition of culture (and, despite various gestures, seeming to forget the insights of many years of anthropology and sociology). Hence, representation,'meaning' and the symbolic are treated as 'cultural', whereas the notion of culture as a 'whole way of life' seems to be rather marginalized or forgotten - or applied only to the selected workers engaged in 'symbolic' activities. So, advertising executives, designers and magazine journalists are cultural intermediaries, whereas it seems that biologists, physicists, accountants, priests and trade union leaders are not. Yet there are many other occupational groupings that are crucial to processes of cultural mediation or the linkages which might connect consumption with production. Indeed, a consideration of who might bridge this space, or who might be involved in 'articulating' production with consumption, raises some significant questions about the enduring distance between production and consumption.

I want to develop this point further by focusing on two groupings of workers engaged in many of the symbolic practices attributed to 'cultural intermediaries', but who do not perhaps occupy the type of petite bourgeoisie 'class position' implied by Bourdieuian notions of cultural intermediaries. The first group is comprised of senior managers or senior corporate executives, business analysts and accountants - the people who are often routinely referred to as 'the suits' (in the music business, Hollywood and the advertising industry), a term that is in many ways a romantic conceit that is deployed 
rhetorically within such industries during various classification struggles and as a means by which the so-called 'creatives' attempt to establish their distance from the demands of budgets and

Financial constraints ('the suit' being the index of such constraints). Accountants are key intermediaries who are called upon to deploy their given expertise at moments when uncertainty (or risk) is pervasive; when senior executives (in the music or film industry) are unclear how to judge the creative abilities of the staff they have appointed; when corporations need to assess their portfolio of artistic assets (whether books, authors, musicians, recordings, etc.); or when a company involved in cultural production is assessing their attempts to construct or imagine the public as a market.

Accounting knowledge has emerged as a particular way of ordering and assessing the actions of individuals within multi-divisional corporations. It provides away of privileging 'hard' data (facts, figures, statistics) over 'soft' explanations (human foibles, intuitive hunches and 'belief in an artist'). Yet, the procedures of accounting are by no means as objective, straightforward or guided by rational 'economic' calculation, as is sometimes assumed. Geert Hofstede, following his experience of working in various industries and from years of research, reached the conclusion that accounting systems are little more than 'uncertainty-reducing rituals'. Accountants fulfil 'a cultural need for certainty, simplicity and truth in a confusing world, regardless of whether this truth has any objective base' (Hofstede, 1991: 151). Certain actions are reduced to figures and these are then abstracted out of the social context within which they were created and which they seek to explain. Hofstede argues that corporate budget practices are often little more than a 'game', driven less by any clear financial logic than an attempt to maintain morale in the face of uncertainty.

There is a considerable body of work, itself owing a debt to the writings of Max Weber, which suggests that accounting knowledge is grounded in very specific spatial and historical circumstances and which points to the way that accountants continually produce changing symbolic representations that are historically specific (see Jones, 1995). In addition, accountants do not simply 'account' in some instrumental way anymore than talent scouts solely assess 
'talent' without any consideration for budgets, the commercial 'market' or financial matters. The significance of accountants and business affairs staff is severely down played if they are simply reduced to 'suits' and assumed to have little understanding of and contribution towards the creative process. Whilst the high powered executives and star artists may continually move between the few major entertainment corporations and whilst a continual stream of young staff may come and go, financial analysts, legal staff and accountants can remain with the same corporation for many years and provide a source of stability, often remaining with a company for years and enduring changing fashions, the rise and fall of different star personas, and corporate take-overs and mergers.

To give an example from my own work on the music industry, it is usually artist and repertoire $(A \& R)$ staff who are thought of as the initial point of contact for any new artist who may be signing to a company. Yet it is the business affairs people (accountants and lawyers) who will be involved in drawing up the finer details of any contract and negotiating with performers and their representatives. A \& $\mathrm{R}$ staff may provide a hip face, may hang out in the mythical 'street' and club, may discuss song arrangements with their artists and book an act into a studio. But it is business affairs staff who will approve the payments to the studio. If a band find themselves recording on a Sunday morning and suddenly decide that they require additional equipment or session musicians and that this will take them over budget, then it is more usually the signature of the head of business affairs that will release the funds to allow the creative process to continue. Hence, an artist's personal relationship with the director of business affairs is arguably more important than their repartee with the young scout who may have first seen them playing in a club and who may be with a competing company or working in a record shop in two years time. Business affairs staff assess the economic potential of any acquisition over both short and long term. They are then involved in continually monitoring an artist's economic performance and will judge at which point a performer, catalogue or genre is no longer commercially viable. This is not simply a 'financial' decision but impacts upon the symbolic production of the company's repertoire, not only in terms of who is selected to 
remain at the company, but also due to the subtle ways in which the musical preferences of the president of business affairs, and the nature of his or her personal relations with artists, can influence the judgements made.

Hence, it is important to incorporate the work and dispositions of accountants into an understanding of the activities of cultural intermediaries. These workers do not simply represent the financial pressures of 'commerce' (counterposed against art or creativity). They are involved in the construction of what is to be 'commercial' at anyone time, often retrospectively, and they are engaged in mediating many of the values through which aesthetic work is realized (Negus, 1995, 1998). If we are to understand the more general relations between production and consumption, then we need to understand the symbolic, and the cultural in the broadest sense of the term, as well as the narrowly economic practices of business analysts and accountants. We should also think about the ties that bind 'cultural intermediaries' firmly into these established institutionalized structures of production.

One such connection can be highlighted by considering the work of a well established occupational group with a direct relationship to 'cultural intermediaries' - workers in a factory. The activities that take place in the manufacturing plant or assembly line may be less apparent than the cultural service work of editors, journalists and designers, due to the geographical location (and relocation) of factories and warehouses to parts of the country, city or world where labour is cheaper or concealed. In numerous industries involved in cultural production, the work of the so-called 'creatives' is often far removed from the manufacturing process. This is an issue that is highlighted by Angela McRobbie (1998) in her work on the fashion industry, where she observes that fashion students tend not to visit factories and production units. Designers often have little knowledge of who makes up their clothes, how much they are paid and where it is done. The 'creative' impulse breeds a certain distaste for, denial of and even contempt for the day-to-day realities of manufacturing labour and warehouse work. Cultural intermediaries are in significant ways prone to encourage the establishment of a distance between themselves and industrial manufacturing, storage and shipment of the symbolic items that they have a stake in 'mediating'. 
In a similar way, those who are apparently being encouraged to get ever closer to consumers - personnel working in retail (du Gay, 1996) - are often equally unaware of the biographies of the products they are selling on a daily basis. This can be as true of the latest fashionable training shoes or dresses, electronic components or coffee beans, which may all be extracted from sweated and impoverished labourers, as it is of the artisanal, 'traditional' crafts produced by peasants. As Nestor Garcia Canclini $(1982,1993)$ found in his research on 'popular cultures' within capitalism in Mexico, those employed in stores and boutiques selling 'traditional' crafts often had no idea where the articles they were selling had come from. They had no knowledge of who had produced them, nor were they aware of the original purpose of such artifacts (they had simply become 'authentic' folk souvenirs for tourists). In part, this situation had come about as a direct consequence of the activities of a group of workers whom Garcia Canclini identifies as 'intermediaries' linking the town to the remote village, connecting the peasant farmer to the urban entrepreneur, and who were engaged in integrating a 'traditional' form of production into the commodity system and modern capitalist relations of market exchange.

Some studies have shown that the cultural intermediaries of marketing and public relations can play a critical role in connecting production to consumption in such a way that their practices can shape the product and, in some significant way, feed the practices of the public back into the design and marketing process as a form of social knowledge (du Gay et al., 1997). But this is not always the case. Far more frequently, there is no enduring 'articulation' nor substantive dynamic linking production with consumption. Instead, there are fleeting moments of contact as products are passed from workers aligned more according to Jean Paul Sartre's (1976) notion of series, relating to each other through the most habitual and superficial of unreflexive transactions conducted because they are simply in close proximity due to their conditions of employment, rather than in the reciprocal way suggested by the notion of 'intermediary' activity.

There are also indications of significant knowledge gaps, and clear evidence that employees engaged in intermediary activity - knowledge workers, those 
working with information and symbols - are involved in attempting to plug these gaps. If the work of cultural intermediaries entails the production and circulation of information and symbolic materials, so it also involves the concealment of knowledge, deception and manipulation (widespread within advertising and marketing, and at its most apparent in some of the publicity and public relations work to be found in the music and film industries). As Arjun Appadurai has observed, as artifacts move over ever greater distances from producers to consumers 'so the negotiation of the tension between knowledge and ignorance becomes itself a critical determinant of the flow of commodities' (1986: 41). As this occurs, cultural intermediaries are required to find ways of becoming ever more adept at masking and obscuring this tension between corporate knowledge and public ignorance. It is, therefore, important that research does not neglect the full range of conditions and practices entailed in this type of intermediary activity, particularly those deliberate attempts to distort and conceal information, or circulate false ideas.

I have been making a number of general points in this section, two I wish to stress. First, the emphasis on a certain conception of cultural intermediaries tends to result in other occupations not appearing in the frame, occupations that are crucial to the commercial and institutional mediation of cultural forms, practices and artifacts (and certainly for an understanding of the mediations of production/consumption within contemporary capitalism). Whilst it would be unhelpful to broaden the category of 'cultural intermediaries' to include such other workers and activities, we should certainly not draw an artificial boundary around these privileged symbolic practices and neglect the way they are integrated into and operate in direct relation to a range of intermediary activities. Second, the focus on this specific conception of cultural intermediaries fails to adequately interrogate the gaps or spaces between production and consumption. It takes the apparent symbolic fit between producer and consumer (the presumed effectiveness of publicity and 'consumer intelligence') at face value, and neglects how the growth of a cluster of 'culture industries' dependent upon advertising imagery, promotional techniques and marketing methods have 'widened the distance . . . between producers and consumers' (Garnham, 2000: 162). The increasing use of 
publicity, public relations and marketing, and other symbolic intermediary activity, has not necessarily resulted in production and consumption being brought closer together. Instead, it has exaggerated the space between the product (or performer) and the public. Cultural intermediaries are frequently offered to us as workers who are filling this gap and making the connection. But, like much of the imagery, words and symbols they are engaged in constructing and circulating, they offer the illusion of such a link rather than its material manifestation. Cultural intermediaries reproduce rather than bridge the distance between production and consumption.

\section{How creative, active and reflexive are cultural intermediaries?}

The workers who are characterized as cultural intermediaries tend to be accorded an active, self-conscious, reflexive and creative role in their particular activities. This accent is apparent in the writings of Bourdieu and Mike Feather-stone, and also in the work of those authors who have adopted this concept in their research (e.g. O'Connor and Wynne, 1996). This emphasis seems even more so now that there is a distinct tendency to speak of the 'creative industries', a trend that the British Labour Government has both latched on to and has been instrumental in propagating as part of its economic and cultural policies. Yet many of the practices that have been identified here, and subject to academic study, might involve activities that are rather more habitual and routine than has sometimes been implied or described. On this point it might be work relocating the work of cultural intermediaries and placing it within a longer tradition of thinking about the occupational practices of people who intervene between production and consumption, particularly those involved in the arts, media and formal institutions of cultural production (if, as is assumed, 'cultural intermediaries' are most prominent in advertising, radio, television, print journalism and the general circulation of symbolic forms).

Up until the 1970s and into the 1980s, research into the working worlds of media organizations and commercial cultural production, was dominated by the concerns of occupational sociologists and mass communication researchers and, despite being subject to considerable critique, this type of 
research has by no means disappeared. There is a substantial body of work that focuses on those involved in 'boundary spanning roles', a term used by Paul Hirsch (1972) in writings published during the late 1960s and early 1970s when he focused on the music business, book publishing and film industries. Hirsch thought of the linkages between production and consumption through the metaphors of 'filters' and 'flows' and by utilizing the concept of the gatekeeper. As is well known (for an overview see Tumber, 1999; McQuail, 1994), this notion emerged in early communication studies of the 'production of news' and was initially posited as a challenge to the idea that news is simply a reflection of events 'out there' in the world. The gatekeeper concept sought to stress the editorial selection of very particular stories and hence the production of partial versions of complex events. Although developed from the study of news, a generalized model of the gatekeeper was adopted by various writers seeking to stress how key personnel control access to cultural production: the editors who decide which authors will have their books selected for publication; the talent scouts who decide which songs and recordings will be selected; or producers who decide which movie ideas or scripts will be developed (see Ettema and Whitney, 1982).

Taken alone, the gatekeeper concept is limited by the assumption that cultural items simply appear at the 'gates' of the media or culture producing corporation where they are either admitted or excluded. Not only is content actively sought out (someone has to go and find the talent or the story), it can be systematically planned, with staff in the organization deciding in advance the genre of story, music or film they are seeking and encouraging its internal construction or sub-contracted production. However, if linked with an awareness of the various internal occupational routines and organizational values guiding the construction of cultural artifacts within organizations, this literature can be useful for providing an insight into the habits and routines within media and culture producing organizations. Indeed, perhaps one of its key insights is to highlight how symbolic material is constructed as a result of very well established routines that require little effort or sourcing (up-dating old stories, re-writing old songs, re-packaging old programmes or novels). Such routines make working life easier (enabling workers to deal with the 
pressure of time, deadlines and production schedules - to keep the presses rolling or the manufacturing plant running). These routines also introduce a sense of certainty or predictability into the process, encouraging the adherence to formulas and patterns of working that have proved successful in the past. Whilst much of the literature that focuses on these processes is far removed from debates about the activities of new cultural intermediaries it is clearly relevant to any consideration of the occupational activities of this class fraction, and would suggest that a large amount of work involving 'symbolic goods and services' may be conducted through the adherence to standardized occupational formulas and generic conventions, and operating within rather than across the boundaries of organizations.

In signposting this body of research I am not suggesting that such routines simply dominate or that this should be a sole focus of attention. I am arguing that any study of cultural intermediaries should incorporate an awareness of the research that has stressed the habitual, unreflexive and uncritical adherence to well established production routines and occupational formulae (even if many of these ideas might seem lost amongst some of the less inspiring writings about 'mass communication'). In arguing this I am also not implying that more recent research has not challenged this body of work, nor shown its various limitation. My point is rather to argue that we should develop an ability to untangle or disaggregate the practices of cultural intermediaries: to work out when, how and under what conditions such aesthetic activity might be creative, innovative and providing any more than an impetus inclining towards the conservative and mundane. This seems particularly important if we take it, as Nixon $(1996,1997)$ suggests in his writings on this subject, that these workers have been judged to manifest certain progressive tendencies that challenge existing social and cultural hierarchies. There is perhaps a need for a greater sense of when and how the routines, habits and codes are broken or maintained; by who, in what ways and with what consequences. 


\section{Strategies of inclusion and exclusion}

In his writing on the role of advertising practitioners, Nixon (1997) has also argued that we need a more 'differentiated picture' of cultural intermediaries, one which is sensitive to differences aligned with educational background and training, and which is aware of issues of gender and race. I endorse this point, but would go further and ask that we question some of the assumptions about the pluralism, and fluidity of movement into the occupations of those involved in new forms of cultural production, particularly some of the assumptions about their apparent openness.

In Bourdieu's formulation, cultural intermediaries are characterized as occupying a position where 'jobs and careers have not yet acquired the rigidity of the older bureaucratic professions' (Bourdieu, 1984: 151). Entry into these occupations is usually via networks of connections, shared values and common life experiences. Gaining access to work is less dependent upon a meritocracy or assessment and recruitment according to formal qualifications. Bourdieu's conclusions were reached following empirical research conducted in the 1960s, yet this point has been continually stressed by subsequent writers. For example, Justin O'Connor, taking up this theme, writes of how cultural intermediaries become ever more significant in contributing to social change in what he calls 'an a era of post-scarcity' when 'the cultural hierarchies are much more fragmented and plural' (1999: 7).

But, to what extent is this any more or less open? We need to ask more questions here about who is admitted or excluded, how this occurs and how it might vary across different arts and media industries. Anecdotally, there is much evidence (in biographies, trade magazines and so on) to suggest that the film industry, for example, is dominated by very strong family connections. Not only are actors and actresses often drawn from very well established family dynasties, so too are producers and directors. In a newspaper profile of the actress Sigourney Weaver, to cite one case, it becomes clear that the recognition of her talent and her subsequent success has been facilitated by the environment, economic support and cultural capital provided by a 'family background' of 'entertainment aristocracy' (Mackenzie, 2000: 11). Less within the elite worlds of stardom, in my own work on the music industry in Britain I 
have found clear connections between aesthetic hierarchies, working practices within companies and broader class divisions.

Researching in the late 1980s and then into the 1990s (Negus, 1992, 1999), I found that most of the key decision makers within the British music industry shared many features in common and have come to constitute a coherent class grouping. Those executives who have been in the business for 25-30 years and who find themselves in senior management or running labels have been drawn from a very particular class background and habitus. Recruited into the music industry during the 1960s and early 1970s, most senior executives are middle-class, white males who have received a privately funded education at 'public schools', or attended state grammar schools, and completed studies at university. Their formative experience has been shaped during the era when rock was gaining cultural value, becoming selfconsciously intellectual and respectable; an epoch when various elements of rhythm and blues and rock'n'roll were 'appropriated' and 'rechristened rock or progressive music by its recently enfranchised grammar school, student and hip middle class audience' (Chambers, 1985: 84). A simultaneous expansion of the universities and institutions of cultural production provided an impetus that facilitated the recruitment into the recording industry of a group of mildly bohemian young people associated with the 'counter-culture'. Many of these young executives had initially been involved in booking bands, often as university entertainment officers, and a considerable number had played in rock bands. The 'genre culture' of British rock music provided a particular series of orientations, assumptions, dispositions and values, and these were carried into the organizations of music production and came to dominate agendas within the expanding recording industry. Despite often being presented as a fairly 'liberal' business, populated by personnel who are 'in touch with the street', these agendas were in no way a 'reflection' of the diversity of music being played and listened to in Britain. Instead they represented, in condensed form, the preferences and judgments of a small, relatively elite educated, middle-class, white male faction.

The aesthetic and social consequences of this have been profound. At a decisive phase in its expansion and growth, the British music industry was 
reorganized around a series of dichotomies in which rock artists were favoured over pop or soul performers; albums were favoured over singles and self-contained bands or 'solo artists' who were judged, from a position derived from Romanticism, to 'express' themselves through writing their own songs were favoured over the more collaborative ways in which singers or groups of performers have, for many years, worked with arrangers, session musicians and songwriters in putting together a 'package'. Most obviously, conventional white male guitar bands were treated as long-term propositions, whilst soul and rhythm and blues music came to be treated in a more ad-hoc and casual manner. These distinctions not only informed acquisition policies and marketing philosophies, they were hierarchically inscribed into the drawing up of contracts, and the allocation of investment to departments, genres and artists.

In acquiring new artists, staff in the British music industry have not been responding, in any neutral or obvious way, to the 'talent available' or to 'public demand'. Equally, the working practices that have been institutionalized and which result in these aesthetic and commercial hierarchies are not explicable in terms of formal occupational titles nor straight forward arguments about the type of pressures exerted by the corporate capitalist control of production and distribution. These working practices have emerged and been shaped historically, as a result of broader social divisions within Britain and as a consequence of how the beliefs, practices and aesthetic dispositions of those cultural intermediaries who constitute a 'rock genre culture' have contributed to the formation of a particular type of music industry. These cultural intermediaries, whilst defying certain conventional divisions between work/leisure, continue to maintain boundaries of access and inclusion. Crucial here is the way that these workers have used their access to the cultural industries to maintain a series of rather more traditional and enduring boundaries, social divisions and hierarchies.

If these strategies of class exclusion have characterized the music industry (often considered to be one of the most accessible and liberal of businesses) then it is clear that comparable patterns can be found in other industries involved in providing symbolic goods and services. A case in point is 
presented by James Curran (2000) in his account of the frameworks of cultural values and social networks that bind together magazine and newspaper literary editors, publishers and novelists. Currans' study provides an example of how a relatively small literary network shapes the acquisition, hierarchical promotion and critical judgments made about books and authors. A range of biographical and anecdotal material suggests that this is also the case in the theatre and the fine arts.

With this in mind, my final point is to ask to what extent the activities and lifestyles of cultural intermediaries have posed any challenge to traditional elites or dominant classes? To what degree do the new cultural intermediaries make use of well established and rather more traditional ways of maintaining power, position, privilege and patronage? These are questions that surely need to be addressed via a thorough analysis of the power relations involved, if we are to gain a fuller understanding of the consequences of the working practices that are proliferating at the moment where production meets consumption. Particularly if, as is implied in much of the writing on cultural intermediaries, a cultural politics is presumed to be possible at the point where production/consumption articulate, at the connecting point rather than within the discrete arenas of consumption (resistance and appropriation) or production (ownership and control). With its emphasis on the broader social significance, creativity and potential autonomy of a specific section of workers engaged in 'providing symbolic goods and services', it is perhaps ironic that the notion of 'cultural intermediaries' has been adopted from the work of Bourdieu, yet deployed in a manner that is prone to a strand of romanticism quite at odds with Bourdieu's project.

\section{References}

Appadurai, Arjun (1986) 'Introduction: commodities and the politics of value'. In A. Appadurai (ed.) The Social Life of Things. Cambridge: Cambridge University Press, 3-63. Bourdieu, Pierre (1984) Distinction. A Social Critique of the Judgment of Taste. London: Routledge.

— (1993) The Field of Cultural Production. Cambridge: Polity.

_ (1996) The Rules of Art. Cambridge: Polity. 
Chambers, Iain (1985) Urban Rhythms, Pop Music and Popular Culture. Basingstoke: Macmillan.

Curran, James (2000) 'Literary editors, social networks and cultural tradition'. In J. Curran (ed.) Media Organisations in Society: London: Arnold, 215-39. Du Gay, Paul (1996) Consumption and Identity at Work. Sage: London. Du Gay, Paul, Hall, Stuart, Janes, Linda, Mackay, Hugh and Negus, Keith (1997) Doing Cultural Studies: The Story of the Sony Walkman. London: Sage.

Ettema, James and Whitney, D. Charles (eds) (1982) Individuals in Mass Media Organizations: Creativity and Constraint. London: Sage.

Featherstone, Mike (1991) Consumer Culture and Postmodernism. London: Sage.

Garcia Canclini, Nestor (1982) Las Culturas Populares en el Capitalismo. Mexico: Nueva Imagen.

_ (1993) Transforming Modernity:Popular Culture in Mexico. Austin, TX: University of Texas Press.

Garnham, Nicholas (2000) Emancipation, the Media and Modernity. Oxford: Oxford University Press.

Hirsch, Paul (1972) 'Processing fads and fashions: an organisational set analysis of cultural industry systems'. American Journal of Sociology, 77(4): 639-59.

Hofstede, Geert (1991) Cultures and Organizations. London: McGraw-Hill International.

Jones, T. C. (1995) Accounting and the Enterprise. London: Routledge.

Mackenzie, Suzie (2000) 'In a galaxy of her own'. The Guardian Weekend, 22 April, 10-15.

McQuail, Denis (1994) Mass Communication Theory. London: Sage.

McRobbie, Angela (1998) British Fashion Design. London: Routledge.

Negus, Keith (1992) Producing Pop: Culture and Conflict in the Popular Music Industry. London: Arnold.

- (1995) 'Where the mystical meets the market; commerce and creativity in the production of popular music'. The Sociological Review, 47(2): 316-41.

- (1998) 'Cultural production and the corporation: musical genres and the strategic management of creativity in the US recording industry'. Media, Culture and Society, 20(3): 359-79.

(1999) Music Genres and Corporate Cultures. London: Routledge. Nixon,

Sean (1996) Hard Looks: Masculinities, Spectatorship and Contemporary

Consumption. London: UCL Press. 
_ (1997) 'Circulating culture'. In P. du Gay (ed.) Production of Culture/Cultures of Production. London: Sage, 177-234.

O'Connor,Justin (1999) 'Popular culture, reflexivity and urban change'. In Jan Verwijnen and Panu Lehtovouri (eds) Creative Cities: Cultural Industries, Urban Development and The Information Society. Helsinki: University of Art and Design.

O'Connor, Justin and Wynne, Derek (eds) (1996) From the Margins to the Centre: Cultural Production and Consumption in the Post-Industrial City. Aldershot: Arena, Ashgate.

Peterson, Richard (1976) 'The production of culture. A prolegomenon'. In R. Peterson (ed.) The Production of Culture. London: Sage, 7-22.

Ryan, John and Peterson, Richard (1982) 'The product image: the fate of creativity in country music songwriting'. In J. Ettema and D. Whitney (eds) Individuals in Mass Media Organizations: Creativity and Constraint. London: Sage, 11-32.

Sartre, Jean Paul (1976) Critique of Dialectical Reason. London: NLB. Tumber, Howard (ed.) (1999) News: A Reader. Oxford: Oxford University Press. 